\title{
The urban regeneration's framework for transit villages in Qatar: the case of Al Sadd in Doha
}

\author{
Raffaello Furlan $^{1}{ }^{\mathbb{D}} \cdot$ Sara Zaina $^{1} \cdot$ Shikha $^{\text {Patel }}{ }^{1}$
}

Received: 23 January 2019 / Accepted: 1 July 2020 / Published online: 12 July 2020

(c) The Author(s) 2020

\begin{abstract}
In the past two decades, Doha, the capital city of the State of Qatar, has undergone a rapid urban transformation. In 2013 and 2014, the State of Qatar, respectively, initiated the construction of Doha Metro and launched the Qatar National Development Framework (QNDF), an action plan for managing sustainable urban development at national level. Namely, QNDF emphasizes the importance of linking Doha Metro system with urban growth through transit-oriented developments (TODs), a model maximizing the integration between transport systems and land use, through the development of sustainable, vibrant, livable, compact and mixed-use communities. This research study focuses on Al Sadd, a mixed-use neighborhood located in the center of Doha. Al Sadd is considered a significant site for investigating the extent to which the TOD model can contribute to enhance standards of urban living and fostering a long-term urban sustainability. The strategy for monitoring and assessing the potential benefits of the investigated TOD is grounded on the on-site analysis (based on graph theory) of two indices: (1) built environment diversity and density and (2) travel behavior. The revealed comprehensive approach for the urban regeneration of the Al Sadd TOD is based on a framework for enhancing its (1) mixedused urban fabric and (2) multimodal transportation systems. In turn, the proposed framework provides insights to move incrementally toward interdisciplinary research and governance for TOD in Qatar and in the globalizing GCC, through a long-term sustainability perspective.
\end{abstract}

Keywords Urban regeneration · TODs · Standards of urban living · Doha Metro · Al Sadd · Graph theory

Raffaello Furlan

raffur@gmail.com

Sara Zaina

sara_m_zaina@hotmail.com

Shikha Patel

shikham@qu.edu.qa

1 Qatar University, College of Engineering, Department of Architecture and Urban Planning, Doha, State of Qatar, Qatar 


\section{Introduction}

Globally, about 55 percent of people live in urban areas, according to World Bank Estimates. Currently, cities around the world are experiencing social, economic and environmental issues and challenges, due to globalization and rapid urbanization (Burdett and Rode 2018). Namely, Gulf Countries are facing rapid urban development, which is termed as "instant." As a result, the physical transformation of the built environment is compromising local social, economic and environmental aspects. Namely, Doha, the capital city of Qatar, is witnessing the construction of mega projects under the 2022 FIFA World Cup preparation and 2030 Qatar National Vision (QNV-2030). Qatar's urban expansion is causing threats such as urban fragmentation, urban sprawling, traffic congestion, creation of urban voids, high per capita carbon dioxide emission, non-functional streets in different cores of the city, wider roads and poor walkability networking (Furlan and Sipe 2017; MME 2008).

Additionally, the winning bid for FIFA 2022 boosted the need for a functional public transportation system. As a result, in 2013 Qatar Railways Company initiated the construction of Doha Metro project, consisting of four lines-the Red line connecting the north to the south coastal regions, the Green line connecting Education City to Doha's cultural core, the Golden line running from east to west along the historical districts, and the Blue line running within the inner-city of Doha-which have been partially operational since late 2019 (Furlan 2019; Saeed and Furlan 2019).

Doha Metro system in Qatar, aiming at establishing transit zones in major city cores, is also supported by Metrolink buses, metro express public carriers and trams to ensure a smooth origin-destination experience. This will not only encourage people to use public transport but also bring Qatar a step forward to achieve sustainable development goals of QNV-2030.

QNV-2030 envisions the territorial development of transit villages, or Transit Oriented Developments (TODs), as a comprehensive planning model ensuring that the development of the urban fabric, mixed-use facilities, activity nodal areas and public services are centered around multimodal transit stations. TODs are expected to fulfill the vision of sustainable urbanism by enhancing livability within communities, fostering sustainability and promoting equity in the society (Furlan et al. 2018; Knowles and Ferbrache 2019).

However, it is argued that GCC cities need a more contextualized urban planning approach to the one adopted in the past. Doha Metro project incorporates the planning of major urban cores around the new metro stations. Al Sadd is a distinctive mixed-use neighborhood with a potential to transform as a transit hub or TOD. Therefore, the aim of the study is to define a contextualized planning strategy for the urban transformation and regeneration of the Al Sadd TOD, aiming at enhancing standards of urban living. The proposed framework will provide valuable insights to move incrementally toward interdisciplinary research and governance for transit-oriented development in Qatar and in the globalizing GCC through a long-term sustainability perspective. 


\section{Background}

\subsection{Transit-oriented development: assessment tools}

Efficient transit-oriented development (TOD) provides a livable neighborhood to its citizens with a mix of uses and amenities, fully accessible at walking distance (Fagan 2009). Even though the standard definition of TOD is meant to provide a universal solution to different contexts of sites, variations such as "Urban TOD" and "Neighborhood TOD" refer to the contextual understanding of the site "catchment area" for "walk and ride" transit users (Dittmar and Ohland 2012). Hence, it is argued that the tools for assessing the success and failure of TOD are dependent on its context. Assessing the outcome of a TOD depends on both the efforts of local governments (in terms of policies, strategies and guidelines) and a detailed on-site analysis of the selected TOD. A research study on American cities by "Living Cities" stresses that the popular tools for assessing transit-oriented developments relate to the assessment of livable communities, station area planning, community effort, right-sizing parking, shared parking, aesthetic zoning, collaboration (public-private partnerships), joint development, land assembly and housing trust funds (Fagan 2009).

Also, a research report from the University of Minnesota highlights that transit stations along a specific corridor are assessed through 3 parameters: travel behavior, built fabric and community strength. However, these parameters are applicable along the TOD corridor and, therefore, the performance of each station is required to be assessed through further detailed microscale assessment tools (Suzuki et al. 2013).

Commonly, TODs are compact, mixed-use areas planned to maximize accessibility to public transport and affordability of housing. They feature pedestrian/cycling-oriented environment, attractive building facades, vibrant streetscapes. TODs are typically characterized by a transit station or stop at their center (train station, metro station, tram stop or bus stop), with major facilities and amenities located within a radius of 400-800 m from a transit stop, as this is considered to be an appropriate comfortable distance for pedestrians (Alexander 1987; Altoon and Auld 2011; Bernick and Cervero 1997; Besser and Dannenberg 2005; Brown and Dixon 2014; Carmona and Tiesdell 2007; Carmona et al. 2010; Cervero 2000; Curtis et al. 2009; Furlan et al. 2016; Givoni 1989; Haas 2008).

Increasingly, Transit-Oriented Developments (TODs) have grown to become one of the principal driving strategies for economic revitalization, job creation, quality mixed use, community diversity and travel alternatives (Curtis et al. 2009; Daban 2009; Newman 2009; Walker 2011). TOD creates vibrant, liveable, compact, walkable, sustainable mixed-use communities centered on high quality train systems. This setting allows residents to relieve urban congestion and diminish car dependency (Cervero 2000; Dierwechter 2013; Dittmar and Ohland 2012; Furlan and Harami 2020; Knowles 2012; Montgomery 2013). Consequently, TODs have contributed to achieving cardinal sustainable goals of reducing carbon emission and promoting green mobility.

In several North American cities, TODs are planned for solving specific site-based socioeconomic, environmental spatial challenges such (1) traffic congestion, (2) environmental pollution, (3) fragmentation of the urban fabric and (4) ecological and social threats, commonly derived by detrimental effects of decades of urbanization envisioned through the excessive use and/or dependence of private vehicles (Burdett and Rode 2018; Mulley 2012). In the attempt to create a policy for a TOD model, to be applied 
world-widely, the literature provides a set of "good practices" as an overall reference for implementation of urban settlements.

On the other hand, the European perspective highly emphasizes the need for a contextualized TOD-approach, since most of European cities display well-established public spaces along with a mixed-use, dense historical-heritage urban fabric. For instance, a Dutch-based TOD model argues the need to adopt specific contextualized dimensions and criteria to manage transit villages' urban renewal. For example, while TODs models commonly encompass a half-kilometer radius urban area (or a 5-min-walking distance), in the Netherlands, TOD radius is expected to expand to $2-3 \mathrm{~km}$, due to the extend use of bicycles along with the inclusion of dense residential areas around the transit village (Pojani 2015).

The "Transit-oriented Street Design in Beijing" study provides also a TOD-perspective contextualized to China. The study highlights the need to integrate the sociocultural dimension into the TOD's spatial form, by considering the socialist style of urbanism in China. For instance, the TOD street design in Beijing supports biking tracks, bus routes, mixed-use and human scale-built environment, lacking personal security when compared to Western TODs (Gerrity 2015).

Scholar, urban planners and social scientists argue that twenty-first century's city planning must center around a strategy to increase dependence on public transportation, to create livable cities, to reduce per capita household expenditure, land-use inefficiencies and urban sprawl. Consequently, municipalities are promoting public transport systems to be integrated to smart land use or TODs, as medium to high-density, compact, mixed-use developments (primarily commercial-based inner-city TODs and residential-based suburban TODs) accessible to transit hubs or rail stations nodes. Multiple transit options such as walking, cycling and public transport provide higher levels of accessibility to stations and surrounding areas.

\subsection{TODs in Doha: the case study of Al Sadd}

Vernacular Qatari towns were characterized by narrow street networks called "Sikkas" and/ or tight spaces between buildings (Falahat 2014; Shojaee and Paeezeh 2015). The narrow winding streets contributed to maximizing the building footprint within the settlement. The width of the "Sikkas" allowed for the movement of two camels, occupying an approximate 2-3-m wide area (Falahat 2014). The main mode of transportation in the traditional settlement was represented by animals (camels, donkeys, horses), carts (pulled by animals) and walking. Thus, streets were shaped and dimensioned to allow for these specific common modes of transportation to occur (Furlan et al. 2019; Wiedmann and Salama 2019). The introduction of motorized vehicles required the road network to be transformed to accommodate a large number of private vehicles. In turn, this transformed the built environment and compromised aspects related to the vernacular human-scale urban fabric of the city.

The currently under-construction Doha Metro aims to connect the center of Doha to several megaprojects and transit villages around the major metro stations located along four main lines. The main goal of this major public transit system is to reduce the use of vehicles on the road networks, while pursuing the TOD experience, as part of an integrated transportation and land-use strategy, aiding in the urban regeneration of urban neighborhoods. The main challenge is to plan mixed-use, compacted transit villages around metro stations and accompanied facilities to be comprehensively integrated into the urban context of their surroundings, reducing traffic congestion and maximizing standards of urban living (Furlan and Al-Mohannadi 2018; MOT-Qatar 2015; Rizzo 2014). 
This research study aims at exploring the extent to which the metro station can be spatially and functionally interconnected within the built environment of Al Sadd. Currently, the flourishing mixed-use neighborhood displays different types of residences, malls, facilities and commercial establishments. Strategically located in the heart of Doha, the district sits between three main routes of the city, C-Ring Road, Al Rayyan Road and Doha Expressway. The neighborhood is also intersected by major roads such as Al Sadd Street, Suhaim Bin Hamad Street, Al Amir Street and Al Rayyan Road and by the metro line. The neighborhood was an agricultural land before being transformed into an active residential and commercial neighborhood. The name is derived from a plant called "Sadd," found in the eastern region of Qatar. The entire district has been rebuilt and revitalized into a modern neighborhood with medium-to-high rise mixed-use buildings since the 1970s. Al Sadd metro station is one of the 11 stations on Doha Metro's Gold Line. The station is set to run West-East from Aspire zone in the west to Ras Abu Abboud in the east (Fig. 1). The population of Al Sadd has doubled since 1986: Approximately 6000 individuals were counted in 2004 and 14,000 people in 2010 . The age group of the population is mainly between 25 and 45 years. It is evident that $80 \%$ of the population is economically active, which reflects on the commercial activities distribution surrounding the area. A mix of land-use facilitates provides a variety of services for a lively-vibrant community. The existing land uses in $\mathrm{Al}$ Sadd comprise a mix of commercial at 30\%, residential at 39\%, public institutions at $4 \%$ and open space at $27 \%$ of the total area (Fig. 1) (MME 2008).

At present, the site faces urban design challenges due to the lack of strategic planning. Therefore, Al Sadd is a significant site for investigating the extent to which the TOD model can contribute to enhance standards of urban living and fostering a long-term urban sustainability.
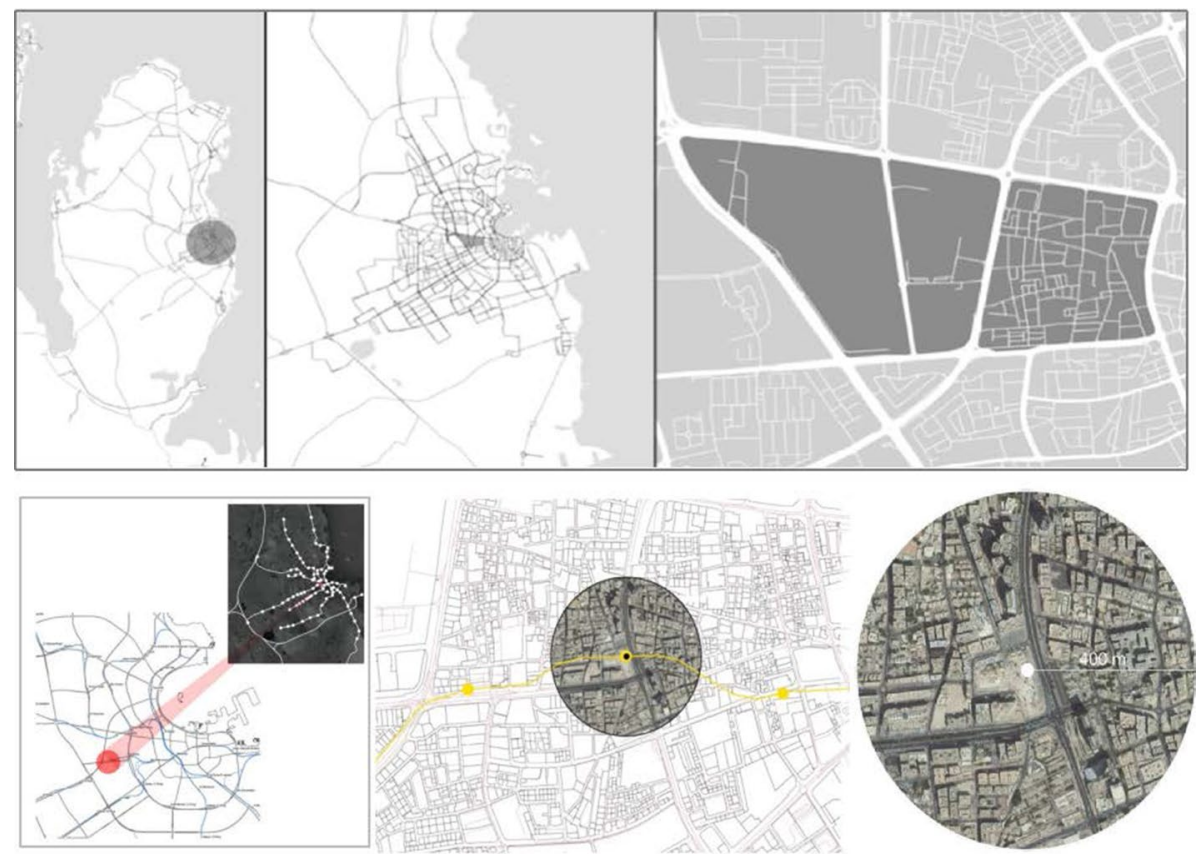

Fig. 1 Location map of Al Sadd area and Doha Metro-Joaan station ( Source: The authors) 


\section{The research design}

This study aims at (1) assessing the transformative potential of the Al Sadd TOD and (2) providing applicable solutions for a future sustainable-TOD model, enhancing standards of urban living, through an on-site analysis based on graph theory, recognized as an efficient way of exploring and assessing qualitatively spatial/territorial indices deduced from literature studies (Denzin and Lincoln 2011; Marshall and Rossman 2014). The research design is structured into 3 stages.

\subsection{Theoretical studies: TODs assessment indices}

The review of the literature contributed to (1) gathering information on significant planning concepts about TOD in an international and regional context; (2) initiating the exploration of the Al Sadd neighborhood and (3) understanding and defining the TOD's assessment indices for assessing the performance of a potential compact public transport-oriented urban node. TODs have become popular models encouraging metropolitan sustainable developments. Therefore, in order to explore the extent to which existing areas or settlements can be transformed to effective transit hubs, it is critical to investigate and define the assessment indices for TOD, as tools measuring the effectiveness of developing a compact public transport-oriented node. As proposed by Renne (2009), the application of a comprehensive assessment indices method, based on physical performances criteria, can be structured onto five key categories: (1) travel behavior, that is, parking and traffic flow; (2) economic diversity, that is, public and private investment; (3) environmental diversity, that is, air quality and energy use; (4) built environment diversity, that is, urban fabric quality, pedestrian friendliness, land use; and finally, (5) social diversity related to diversity, safety and affordability (Renne 2009). Citation analysis was used to review the core literature [journals, authors, source places] (Fig. 1).

\subsection{Data collection and analysis (oral and visual data)}

Being urban design an interdisciplinary and multifaceted field of study requiring a participatory approach in design through the active involvement of end-users, stakeholders and practitioners, the attendance of seminars, talks, exhibitions and conferences on the urban development of the city of Doha as part of local and international events provided a first-hand approach to the detailed information on the aspirations and challenges of Doha's urban scene. Such events include the Traditional Gulf Architecture Week held at Qatar National Library and other academic seminars organized by the Department of Architecture at Qatar University, in addition to dialogue with members of the Ministry of Municipality and the Environment [MME] and other active members in the architectural field in Doha. The primary references include visual documentation, historical/ cartographic maps, architectural drawings and photographs of the Al Sadd area. Secondary references were obtained through a survey addressed in September 2019 to 80 professionals from various governmental agencies such as Ministry of Municipality and Environment (MME), Qatar Rail (QR), Qatar Museums Authority (QMA) and Ashghal Public Works Authority. Two categories out of the five revealed from the review of theoretical studies, (1) travel behavior and (2) diversity and density of the built environment, 
were indicated as the most appropriate for assessing the performance of the selected TOD.

Subsequently, between December and February 2019 focus-group interviews were arranged with 40 participants from the selected governmental agencies. Participants were required to complete via email an anonymous questionnaire in order to highlight the relative importance of each aspect of success for the selected TOD [as per two pre-identified categories]. Also, 40 end-users/citizens/respondents residing in the area were interviewed (semi-structure interviews) and asked to discuss and rate the selected indices and whether further relevant indicators had to be listed in the questionnaire. Importantly, several respondents highlighted the need (1) of measuring air pollution (air quality impact) and fuel consumption's as indicators of TOD, in order to assess the relevant environmental effects of the TOD, and (2) of considering detailed indicators for encouraging built environmental conservation of the selected TOD.

In addition, inductive and deductive methods-gained through participatory observations, direct site-observations, field study and on-site analysis-were utilized for the collection of visual data (cartographic maps, aerial views and photographs). Namely, site analysis based on graph theory provides a way of assessing the transformative potential of the Al Sadd TOD and to identify gaps related to (1) travel behavior and (2) diversity and density of the built environment, indicated as the most appropriate for assessing the performance of the selected TOD.

\subsection{Site analysis and findings: the urban regeneration of Al Sadd TOD}

Research by design is a commonly applied methodology in urbanism and architecture through two steps: (1) territorial analysis of the investigated area and (2) generation of a vision, as a way to produce concrete ideas of the investigated area's metamorphosis, through specific design tools. Particular emphasis is given to the interplay between territorial analysis (on-site analysis based on graph theory) and planning exploration (proposal for a masterplan) (Fucile et al. 2017; Secchi, 2007; Tadi et al. 2017).

The systematic research by design approach consists of reading and comprehending possible inter-dependencies and unlocking potentials between flows at urban design and planning scale. Also, the proposed framework contributes to define a comprehensive approach for the urban regeneration of the selected site and, finally, to provide insights to move incrementally toward interdisciplinary research and governance for transit-oriented development in Qatar and in the globalizing GCC (Fig. 2).

\section{Findings}

The resulting strategy for the urban regeneration of the transit village of Al Sadd is grounded on the dependency between (1) mapping (on-site analysis based on graph theory) and (2) urban design proposal (masterplan). As a result, the proposed framework for the urban regeneration of Al Sadd TOD is grounded on addressing and filling the gaps highlighted through the territorial analyzed design tools of investigation, indicated as the most appropriate for assessing the performance of the selected TOD: (A) built environment diversity (mixed-use) and density and (B) travel behavior (transportation system). 


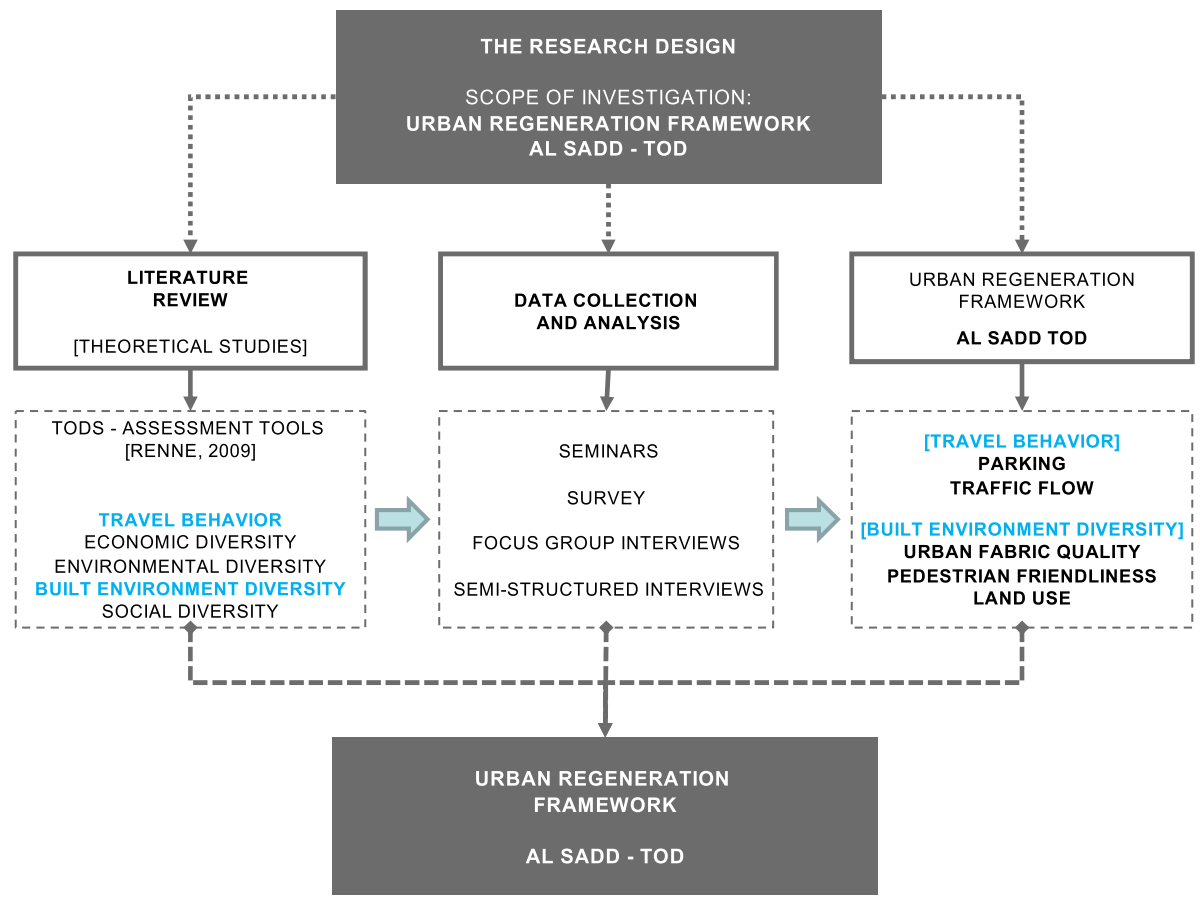

Fig. 2 The research design ( Source: The authors)

\subsection{Site analysis}

\subsubsection{Built environment diversity (mixed-use) and density}

The area is predominantly residential, mixed use with government offices, hotels, shopping center, markets area, community facilities and other civic buildings. Mixed-use and commercial units are majorly found along the main roads. Historic mosques and public amenities for residents such as Government Primary schools, primary health care centers are also present in the areas along minor roads. The site does not also enclose public buildings of particular national and/or historic significance (Fig. 3).

The public realm with public parks or nodes/town squares spaces where people congregate is minimally present: only $10 \%$ of the overall area is occupied by open spaces and public green areas, which are underutilized due to the poor access from the main roads and due to nonexistent green corridors, and discontinued pedestrian network and bicycle lanes (Fig. 4a).

Street parking is clearly visible within the site. Lack of comprehensive city planning strategies resulted in several vacant lots, including unbuilt land and open parking spaces, currently utilized as parking areas. In turn, uncontrolled parking and/or lack of parking regulations, and specifically designated parking areas, cause the residents to park their vehicles in available empty plots around residential and commercial buildings, which also causes discomfort in walking along the existing non-continuous pedestrian sidewalk. Furthermore, roadside's streetscape elements, furniture and planting and 
Land Use of AL Sadd Area in Doha, Qatar - Residential Commercial Vacant Land Public Institutions
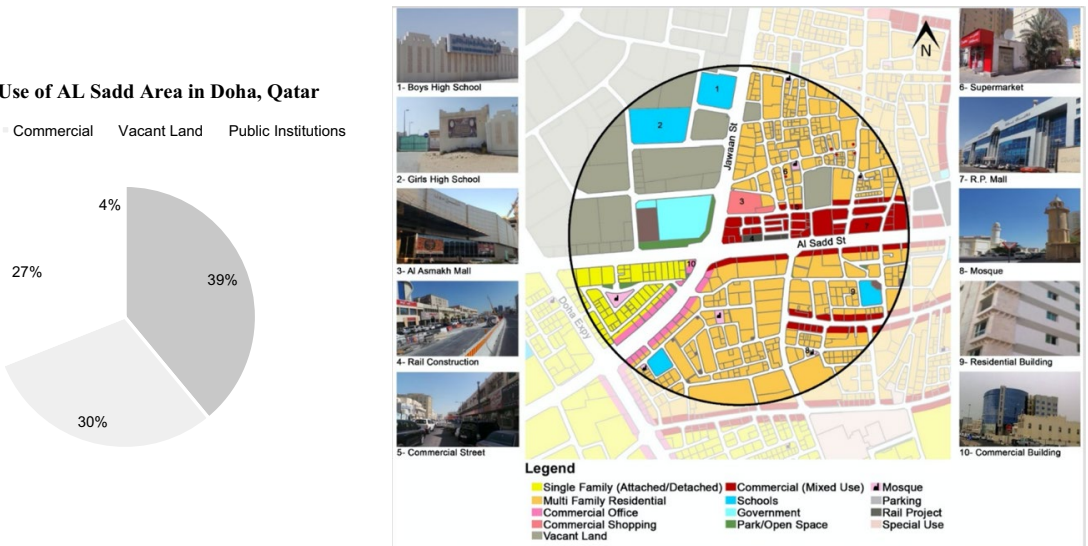

Fig. 3 Land-use map ( Source: The authors)

A

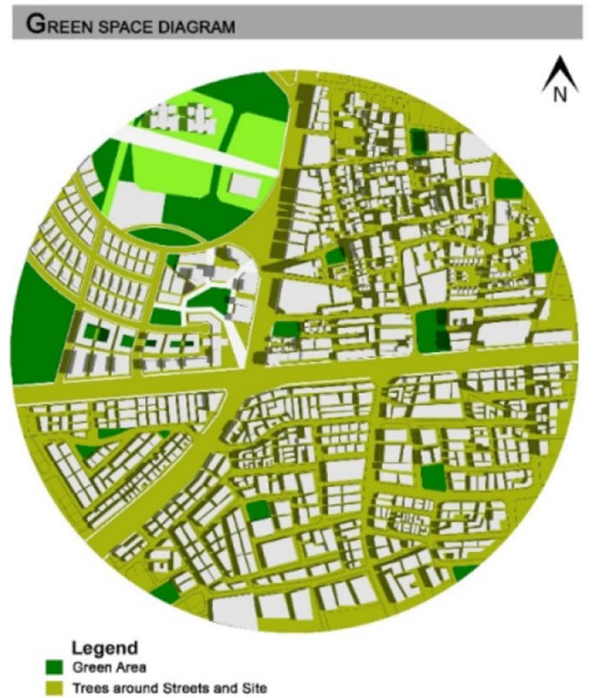

B

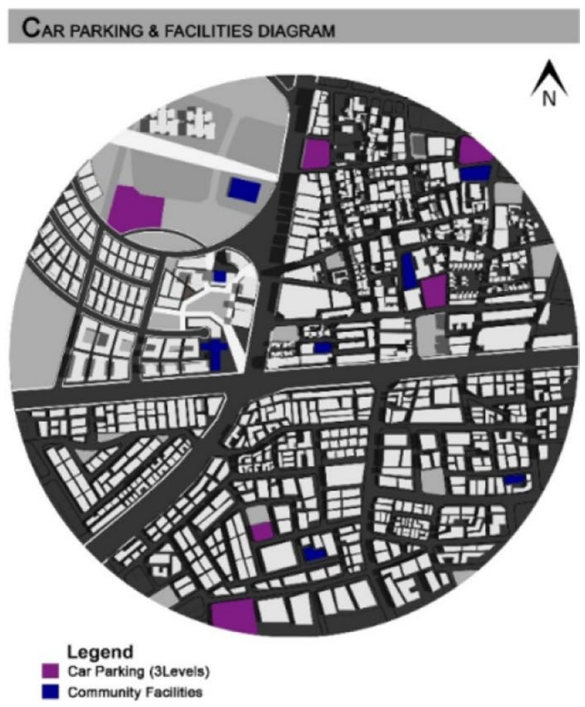

Fig. 4 a Green network; (b) car parking facility ( Source: The authors)

are absent and street pavements are broken and discontinuous, discouraging walkability (Fig. 4b).

The center of the transit village (along the main roads) displays a high-density commercial-retail area with discontinued pedestrian access to on-site retail/service establishments (Fig. 5a). Moving outward, the district is characterized by medium-density residential area, namely by over 6-story apartment buildings with retail shops surrounded by parking areas at the ground floor and 6-story residential compounds. The overall building heights within the area illustrate no building hierarchy, privacy, attractive views and adequate setbacks (Fig. 5c, d). This is due to the lack of planning in regard to height consideration. 

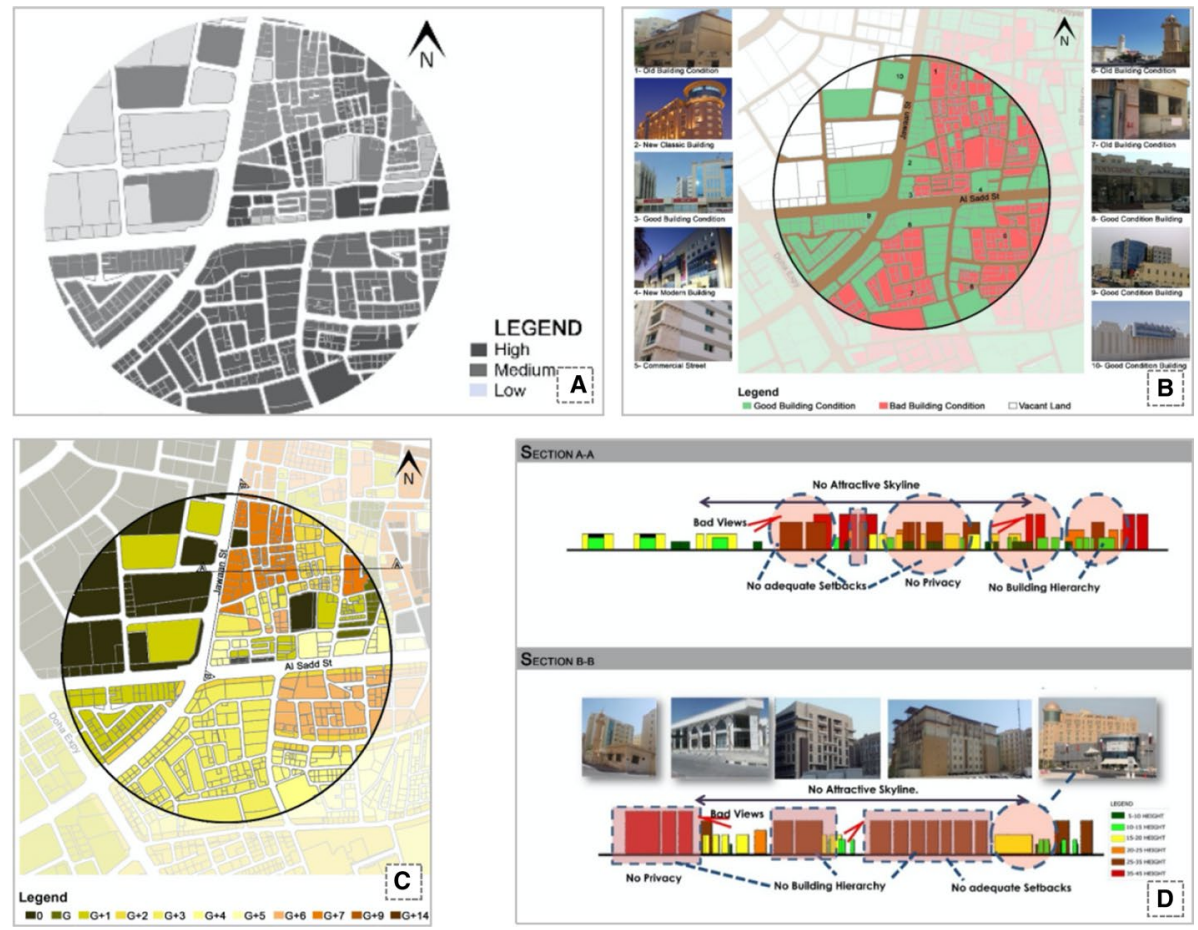

Fig. 5 (a) Density map; (b) condition of buildings $400 \mathrm{~m}$ around Al Sadd metro station; (c) height of buildings $400 \mathrm{~m}$ around $\mathrm{Al}$ Sadd metro station; (d) sections depicting unplanned heights, inadequate setbacks and privacy ( Source: The authors)

(Style) The site displays built forms with various architectural styles and elements which provide a well-suited asymmetric visual aesthetic of the neighborhood. Major high-density buildings and open spaces in the main roads are in acceptable conditions (Fig. 5b). However, residential apartment buildings located in the inner part of the neighborhood are in poor conditions and, consequently, need to be renovated to maintain the traditional architectural style of the area. The poor condition of buildings attracts low-wage laborers, making the area uninviting for middle- and high-income social class and causing unintended segregation.

\subsubsection{Travel behavior (transportation network)}

The Al Sadd TOD (on the metro stations) is approximately $4 \mathrm{~km}$ long from the intersection of the 2 main roads. There are four prevalent modes of public transport in the area, namely private vehicles, taxi, metro and buses accessible within $400 \mathrm{~m}$ from the station (Fig. 6a). Private cars and taxis, along with buses, are the primary mode of travel for the residents. The neighborhood is accessible majorly through the two main crossing roads connecting the site to ring roads. The site displays a distinctive road hierarchy. There are three major roadway types connecting the site: Primary roads are six-lane roads; secondary are fourlane collector roads leading to cluster-areas; thirdly are two-lane access roads leading to single buildings. Road network is well connected with a combination of irregular streets, 
A

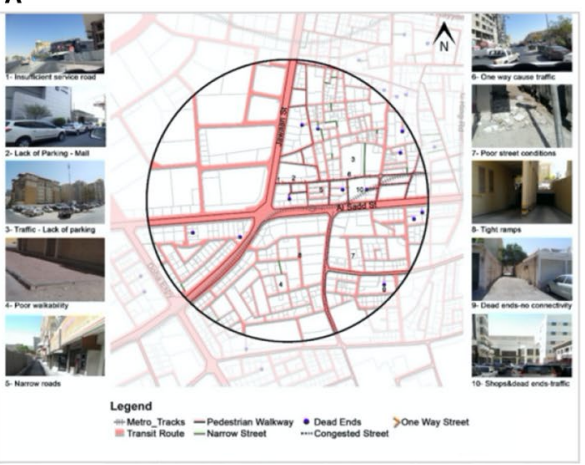

B

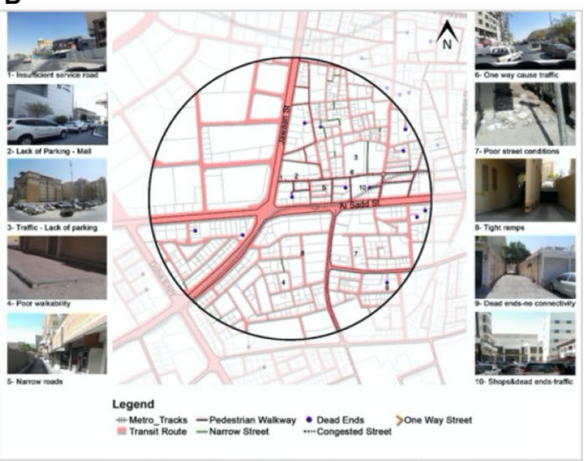

Fig. 6 (a) Transportation and infrastructure map, (b) site analysis of the current 2016 bus station and its 400-m radius context ( Source: The authors)

deformed and regular grids. Except for a few local access roads along residential zones, connectivity in the site is two-way. A few access roads are one way road (the remnants of old urban fabric of Doha) with uncontrolled street parking on each side of the road, causing regular traffic congestion. The major traffic congestion occurs along pick hours on the main six lanes roads leading to the ring roads.

Doha's underused Bus Rapid Transit system, "Mowasalat" buses are majorly utilized by low-wage migrant workers, forming a major workforce in the construction sector and using public transport for traveling to and from these bus stops. Hence, bus stops are accessible to a large population on the main roads but not well connected within the inner suburban areas, therefore, not providing mobility opportunity to residents (Fig. 6b).

Doha is an automobile-dependent city, where most urban areas with large blocks surrounded by multi-lane highways restrain pedestrian accessibility. As anticipated, the existing narrow, often dead-end and one-way streets, which are the remnants of old urban fabric of Doha, were designed to allow pedestrian circulation. Nevertheless, the neighborhood is surrounded with streets that are poorly designed for pedestrian use, with large sidewalks' pavements ending abruptly on street car-parking, lacking continuous, safe sidewalks (pedestrian network), shading devices, streetscape facilities and furniture, and, as a result, contributing to an unsafe pedestrian environment. The on-site analysis within the $400-\mathrm{m}$ area around the Al Sadd metro station, displaying different grade of accessibility from different type of roads, pedestrian network and cycling lanes, reveals that accessibility to pedestrian and cyclist is lacked namely along the internal narrow roads (Fig. 7).

In conclusion, a multimodal transit system is evidently absent. However, the recent opening of Doha Metro has implemented the diffusion and use of buses within the areas around the stations to facilitate users to commute. It is expected that pedestrian pathways and bicycle lanes will be planned and integrated with the urban fabric of the neighborhood.

\subsection{The urban regeneration of AI Sadd TOD}

The systematic research by design approach consists of reading and comprehending possible inter-dependencies and unlocking potentials between flows at neighborhood-planning scale. As a result, the proposed framework for the urban regeneration of Al Sadd TOD is 

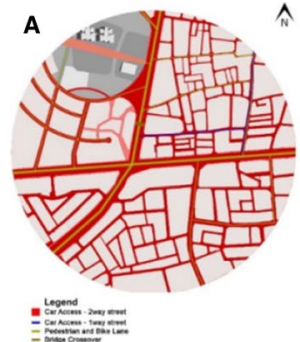
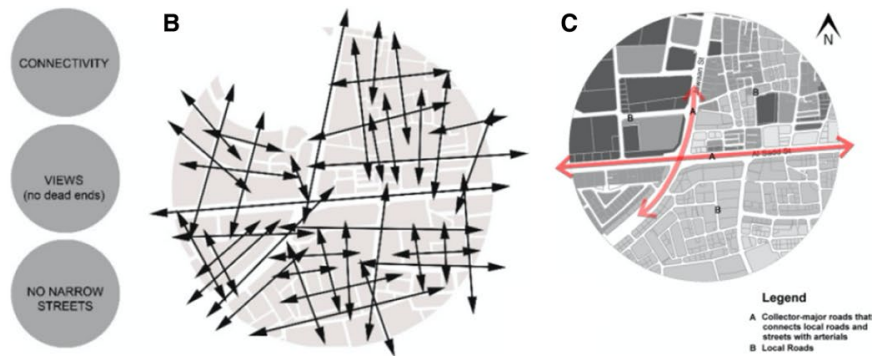

Fig. 7 (a) Connectivity of the site; (b) accessibility and views within the site; (c) map showing connection of sub arterial, collector and local roads ( Source: The authors)

grounded on addressing and filling the gaps highlighted through the territorial analyzed design tools of investigation.

\subsubsection{Mixed-use built environment}

An implemented mixed-use, high-density built environment around Al Sadd metro station would provide opportunities for small retail shops, which would diminish residents' need to drive to larger shopping malls within the area. At street-ground floor level, the intensification of retail stores, restaurants and/or coffee shop would provide the physical settings for a vibrant community. Currently, streets and small open public spaces, forming the primary element of the public realm, are not pedestrian friendly nor attract residents in providing a pleasant street walking experience. Broken pavements and uncontrolled on-street parking aggravate the grade of walkability on site. The area displays several vacant space or plots, which have become sites for unmonitored parking. Similarly, most apartment buildings in the area are not surrounded by private yards at the ground floor, but by sporadic green areas and open spaces utilized as uncontrolled parking areas. The present chaos of haphazard parking along the street can be solved by allocating a dedicated underground parking facility. Lane dieting can also allow the additional area to be used as pedestrian pathways and bicycle tracks.

Existing green areas, such as neighborhood small parks (or playground areas) to be accessed for leisure and relaxation, are either inaccessible or remotely accessible from pedestrians through the neighboring urban fabric. This pattern requires a change of direction in terms of planning, in order to regularizing car parking and increasing accessibility to various distributed green areas: Small parcels should accommodate healthy and safe pedestrian and cycling movement through the urban fabric of the neighborhood. Also, introducing native shady trees and shrubs interspersed with non-native trees such as along the road edge, with proper screening from the roadway can promote a pleasant and secure walking experience (Fig. 8).

\subsubsection{Multimodal transportation systems}

Doha, along with its metropolitan neighborhoods, transformed from a fishing village to multiple centers of economic and urban relevance, due to the presence of energy resources. This form of fast urban growth contributed to the development of car-dominant environment and multi-lane super-block, affecting pedestrian movement and the overall standards 
A
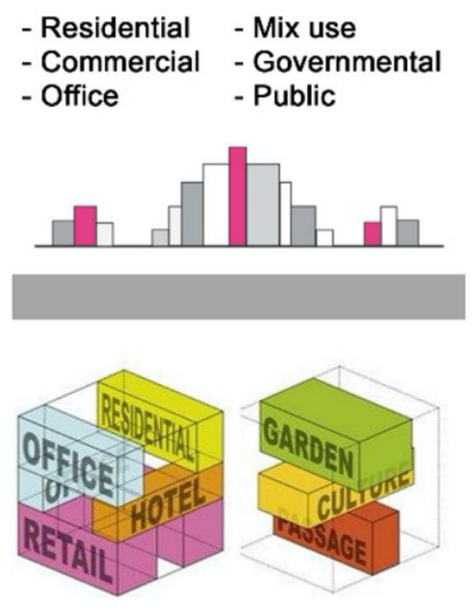

VIBRANT MIXED USE URBAN HUB
B
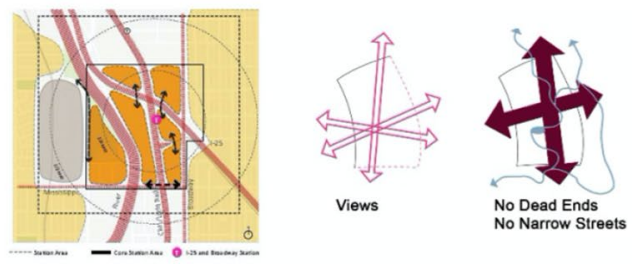

CONNECTIVITY

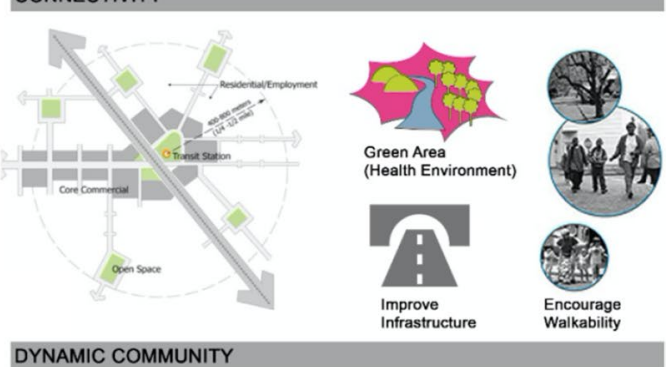

Fig. 8 (a) Planning recommendation based on mixed-use hub; (b) planning recommendations based on the concept of connectivity and diversity ( Source: The authors)

of urban living. Roads and streets are mainly designed for private vehicle use, with no consideration for other sustainable multi-modes of transportation, such as walking and cycling. Moreover, the streets within the district are found to be permeable, with various land uses. Therefore, the aim of the proposed masterplan is to revitalize the study area through an enhanced pedestrian and cycling network, considering the local hot dry climate. Sidewalks, town squares, green parcel areas, parks and green corridors (or infrastructure) should be distributed through the urban fabric and comprise shaded seating benches, street furniture, shaded areas and/or shading devices. Also, introducing streetscaping elements, such as the landscaping and hardscaping elements, and providing street crossings, visible signage along dedicated walking/bicycling lane by lane dieting, would encourage walkability despite the climate extremes and improve the overall TOD experience around the transit station (Fig. 9).

\section{Conclusion and discussion}

In the past two decades, Doha, the capital city of the State of Qatar, has undergone a rapid urban transformation comprising the need for a larger infrastructure network. As a result, in 2013 the State of Qatar initiated the construction of Doha Metro, and in 2014 the Ministry of Municipality and Environment launched Qatar National Development Framework (QNDF), an act comprising a set of plans, guidelines and policy action, for guiding sustainable urban development in Qatar. QNDF emphasizes the importance of linking the new Doha Metro system with national urbanization through transit-oriented developments (TODs), a model maximizing access to public transport and encouraging sustainable urbanism by comprehensively integrating transport systems and land use. The goal is to envision and develop sustainable, vibrant, compact, interconnected transit villages, which contribute to enhance standards of urban living. 

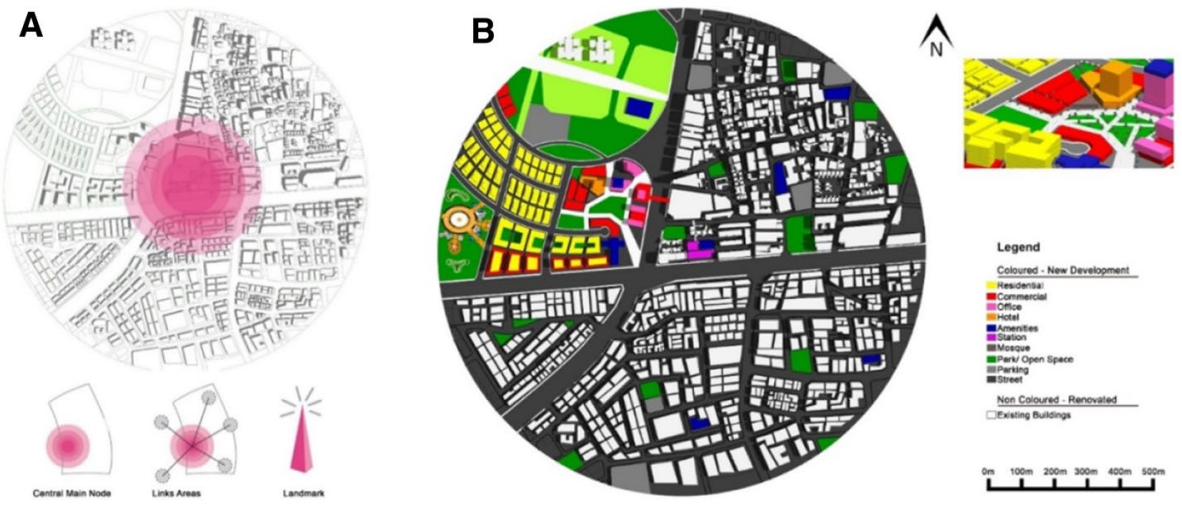

Fig. 9 (a) Diagram depicting the importance of metro station in the neighborhood; (b) map of the neighborhood based on the proposed strategies ( Source: The authors)

The findings revealed through the on-site analysis - based on graph theory-of the assessment tools of (1) travel behavior and (2) built environment diversity highlight that the comprehensive approach for the urban regeneration of Al Sadd TOD must be grounded on a planning methodology for enhancing the (1) mixed-use urban fabric and (2) multimodal transportation systems.

1. In the past decade, Al Sadd area-similarly to other districts-experienced a dramatic augmentation of the number of private vehicles on the road networks, which exacerbated traffic congestion, diminishment of pedestrian mobility and connectivity, misappropriation of the public realm, commonly utilized for on and off-street parking. The city needs to implement urban planning strategies and policies to turn this trend around by replacing existing on-street and surface parking lots with underground car parking facilities, implementing public transit and land-use policies to reduce traffic congestion and encourage smart growth. This comprehensive practice would contribute effectively in enhancing standards of urban living.

2. The quality of streetscape, corridors connecting the public realm through pedestrian and cycling networks is neglected. TOD should be dependent on a singular efficient mode of transport, but it should integrate multimodal systems of transportation, allowing for sustainable mass public mobility within and through the urban fabric of the city. Therefore, the implementation and integration of other transport systems within mixed-use areas should be re-evaluated, namely based on pedestrian and cyclists' accessibility.

As a result of the rapid urbanization and globalization process, the movement of local Arabs toward to outer suburbs has led to a decline and degradation of the urban fabric of historic districts in Doha. As a result, heritage values inherited in the vernacular urban fabric have been threatened and in some case lost. This is affecting (1) the unique sense of identity of the districts, grounded on vibrant, attractive, lively and walkable physical environments and, as a result, the standards of urban living. The urban regeneration of the Al Sadd district through TOD must contribute to create a livable and sustainable district, where people want to reside, walk, gather and linger, and conflicts between vehicles and pedestrians are minimized: This perspective would allow to create a successful, smart, sustainable physical TOD model for Qatar and the GCC. 


\section{Contribution to knowledge}

While there are several theoretical claims, namely from QNDF-2032 and QNV-2030, about the need and benefits of promoting sustainable models TOD enhancing standards of urban livings in Doha, there are no holistic studies exploring the most effective indices for assessing TODs in Qatar and in the region. Therefore, the proposed framework provides insights to move incrementally toward interdisciplinary research and governance for transit-oriented development in Qatar and in the globalizing GCC through a long-term sustainability perspective.

Therefore, this research study provides an opportunity to improve the planning methodology for TOD in Qatar, by developing a strategy for monitoring and assessing the potential benefits and success of the TOD as a planning tool for promoting smart growth and/or sustainable urban regeneration.

Critically, the application and implementation of the proposed framework require the adoption of a comprehensive multifaceted approach, where transportation planners, urban planners and designers, environmental and social scientists and architects merge their effort and knowledge to fulfill the ultimate scope of urban regeneration: enhancing urban quality of life.

\section{Implications for practice and advancement of research}

As Qatar Rail projects are strategized to attain comprehensive connectivity between various stations within the city districts, Al Sadd area metro station could be explored within a larger city scale, with reference to the connectivity to/from adjacent downtown areas. In addition, the research study can be implemented through the collection of data related to supplementary contextualized indices, such as, but not limited to, (1) economic diversity [public and private investment]; (2) environmental diversity [air quality and energy use]; (3) social diversity [diversity, safety, affordability]; (4) sociocultural factors. In turn, this would allow to provide a contextualized comprehensive perspective for the urban regeneration of TODs in the State of Qatar.

Acknowledgements The authors would like to acknowledge the research-oriented vision of Qatar University as an academic institute supporting sustainable development in the State of Qatar. This research study was developed as part of two research project schemes: (1) Collaborative Grant QUCG-CENG-1920-4 titled "The Action Plan for the Implementation of Qatar National Masterplan based on Integration of Land Use and Public Transport Systems", awarded and funded by Qatar University; (2) UREP 23-065-5-001 titled "Sustainable Urbanism for the Urban Regeneration and Preservation of the Cultural-Heritage Site of the Souq Waqif in Doha (State of Qatar)", awarded and funded from Qatar National Research Fund (QNRF, a member of Qatar Foundation). The authors would like to express their gratitude to the leading planners and architects of Qatar's Government Agencies and Ministries, namely the Ministry of Municipality and Environment (MME), Qatar Rail (QR), Qatar Museums Authority (QMNA) and Ashghal Public Works Authority for their collaboration, for participating in the meetings, sharing visual data and cardinal documents relevant to the research aims, and for discussing the results and conclusion of this investigation. This paper was subject to a Double-Blind Peer Review process. Once accepted for publication, the journal 'Environment, Development and Sustainability (ENVI)' offered the authors the choice to publish this article on open access (OA). The open access (OA) publication of this article was funded by the Qatar National Library. Finally, the authors thank the anonymous reviewers for their comments, which contributed to an improvement of this paper. The authors are solely responsible for the statements made herein.

Open Access This article is licensed under a Creative Commons Attribution 4.0 International License, which permits use, sharing, adaptation, distribution and reproduction in any medium or format, as long 
as you give appropriate credit to the original author(s) and the source, provide a link to the Creative Commons licence, and indicate if changes were made. The images or other third party material in this article are included in the article's Creative Commons licence, unless indicated otherwise in a credit line to the material. If material is not included in the article's Creative Commons licence and your intended use is not permitted by statutory regulation or exceeds the permitted use, you will need to obtain permission directly from the copyright holder. To view a copy of this licence, visit http://creativecommons.org/licenses/by/4.0/.

\section{References}

Alexander, C. (1987). A new theory of urban design. Oxford, UK: Oxford University Press.

Altoon, R. A., \& Auld, J. C. (2011). Urban transformation-transit oriented development and the sustainable city. Melbourne, Australia: Images Publishing Dist Ac.

Bernick, M., \& Cervero, R. (1997). Transit villages for the 21st century. New York: McGraw-Hill.

Besser, L., \& Dannenberg, A. (2005). Walking to public transit: Steps to help meet physical activity recommendations. American Journal of Preventive Medicine, 29(4), 273-280.

Brown, L. J., \& Dixon, D. (2014). Urban design for an urban century-shaping more liveable, equitable, and resilient cities. Hoboken, New Jersey (USA): John Wiley \& Sons.

Burdett, R., \& Rode, P. (2018). Shaping cities in an urban age. London, UK: Phaidon.

Carmona, M., \& Tiesdell, S. (2007). Urban design reader. London: Rutledge.

Carmona, M., Tiesdell, S., Heath, T., \& Oc, T. (2010). Public places urban spaces-the dimension of urban design. Oxford, UK: Architectural Press.

Cervero, R. (2000). Walk-and-ride: Factors influencing pedestrian access to transit. Journal of Public Transportation, 3(4), 1-23.

Curtis, C., Renne, L., \& Bertolini, L. (2009). Transit oriented development: making it happen. Cornwall: Ashgate Publishing Company

Daban, G. (2009). A successful TOD will reinforce both the community \& the transit system? Paper presented at the International Conference Series on Competition and Ownership in Land Passenger Transport.

Denzin, N. K., \& Lincoln, Y. S. (2011). The sage handbook of qualitative research. London: Sage Publications.

Dierwechter, Y. (2013). Smart city-regionalism across Seattle: Progressing transit nodes in labor space? Geoforum, 49, 139-149.

Dittmar, H., \& Ohland, G. (2012). The new transit town: best practices in transit-oriented development. Washington, USA: Island Press.

Fagan, L. A. (2009). AOTA's societal statement on livable communities. The American Journal of Occupational Therapy, 63(6), 847-848.

Falahat, S. (2014). Re-imaging the city-a new conceptualisation of the urban logic of the "Islamic city". Berlin, Germany: Springer Vieweg.

Fucile, R., Figlia, L. D., \& Pisano, C., Lucchesi, F., Lingua, V., \& Luca, G. D., (2017). Telling the future. Spatial concepts and metaphors in the representation of strategic visions. Urbanistica, 160, 88-90.

Furlan, R. (2019). Qatar, Doha. In P. D. J. Corcoran, N. Sipe, I. Mateo-Babiano, \& D. Stead (Eds.), Parking: An international perspective. London: Elsevier.

Furlan, R., \& Al-Mohannadi, A. (2018). The practice of city planning and design in the gulf region: The case of Abu Dhabi, Doha and Manama. International Journal of Architectural Research-ArchNet-IJAR, 12(2), 126-145.

Furlan, R., \& Harami, A. (2020). Qatar National museum-transit oriented development: the masterplan for the Urban regeneration of a 'Green TOD'. Journal of Urban Management, 9(1), 115-136.

Furlan, R., \& Sipe, N. (2017). Light Rail Transit (LRT) and transit villages in Qatar: A planning-strategy to revitalize the built environment of Doha. Journal of Urban Regeneration and Renewal, 10(4), 1-20.

Furlan, R., Zaina, S., Zaina, S. (2016). Urban planning in Qatar: strategies and vision for the development of transit villages in Doha. Australian Planner, 53(4), 286-301.

Furlan, R., Petruccioli, A., Major, M., Zaina, S., Saeed, M. A., \& Saleh, D. (2018). The urban regeneration of West-Bay, business district of Doha (State of Qatar): A transit oriented development enhancing livability. Journal of Urban Management, 8(1), 126-144.

Furlan, R., Petruccioli, A., \& Jamaleddin, M. (2019). The authenticity of place-making: space and character of the regenerated historic district in Msheireb, Downtown Doha (State of Qatar). International Journal of Architectural Research-ArchNet-IJAR, 13(1), 151-168.

Gerrity, M. (2015). Global cities being transformed by transit oriented development.Commercial News: Hong Kong Edition. Retrieved from https://www.worldpropertyjournal.com/real-estate-news/hong-kong/transitoriented-development-cbre-perth-city-link-transbay-transit-centre-tod-projects-urban-transit-developmen ts-2015-henry-chin-hong-kong-station-redevelopment-9100.php. Accessed 20 May 2015. 
Givoni, B. (1989). Urban design in different climates. Geneva: World Metereological Organization Publication.

Haas, T. (2008). New urbanism and beyond: designing cities for the future. Random House Incorporated.

Knowles, R. D. (2012). Transit oriented development in Copenhagen, Denmark: from the finger plan to Ørestad. Journal of Transport Geography, 22, 251-261.

Marshall, C., \& Rossman, G. B. (2014). designing qualitative research (3rd ed.). California: Sage Publication.

MME. (2008). Qatar national vision 2030. Doha: General Secretariat for Development.

Montgomery, C. (2013). Happy city: Transforming our lives through urban design. New York: Farrar, Straus and Giroux.

MOT-Qatar. (2015). Qatar highway design manual and Qatar traffic manual.

Mulley, C. (2012). Urban form and transport accessibility. Cheltenham: Edward Elgar Publishing Limited.

Newman, P. (2009). Planning for transit oriented development: Strategic principles. In C. Curtis, \& J. L. Renne, L. Bertolini (Eds.), Transit oriented development: Making it happen (pp. 13-22). Cornwall, UK: Ashgate Publishing Limited.

Pojani, D. (2015). Transit-oriented design in the Netherlands. Transit-Oriented Design in the Netherlands, 35(2), 131-144.

Knowles, R. D., \& Ferbrache, F. (2019). Transit oriented development and sustainable cities: Economics, community and methods. Cheltenham, United Kingdom: Edward Elgar Publishing Ltd.

Renne, J. (2009). Measuring the success of transit oriented development. In C. Curtis, J. Renne, \& L. Bertolini (Eds.), Transit oriented development: Making it happen (pp. 241-255). UK: Ashgate Publishing Limited.

Rizzo, A. (2014). Rapid urban development and national master planning in Arab Gulf Countries Qatar as a case study. Cities, 39, 50-57.

Saeed, M. A., \& Furlan, R. (2019). Transit-oriented development in West Bay, Business District of Doha, State of Qatar. Journal of Cultural Heritage Management and Sustainable Development, 9(3), 394429. https://doi.org/10.1108/JCHMSD-09-2018-0062.

Secchi, B. (2007). Prima Lezione di Urbanistica. Bari, Italia: Editori Laterza.

Shojaee, F., \& Paeezeh, M. (2015). Islamic city and urbanism, an obvious example of sustainable architecture and city. Cumhuriyet Üniversitesi Fen Fakültesi Fen Bilimleri Dergisi, 36(6), 231-237.

Suzuki, H., Cervero, R., \& Iuchi, K. (2013). Transforming cities with transit. Transit and land-use integration for sustainable urban development. Washington, DC, USA: The World Bank.

Tadi, M., Biraghi, C. A., \& Zadeh, H. M. (2017). Urban low carbon energy transition. The New Porto di Mare Eco-district in Milan based on IMM methodology. Urbanistica, 160(54), 110-112.

Walker, J. (2011). Human transit-how clearer thinking about public transit can enrich our communities and our lives. Washington: Island Press.

Wiedmann, F., \& Salama, A. (2019). Building migrant cities in the Gulf-urban transformation in the Middle East. London, UK: Bloomsbury Publishing Plc.

Publisher's Note Springer Nature remains neutral with regard to jurisdictional claims in published maps and institutional affiliations.

Raffaello Furlan holds Bachelors and Masters Degrees from IUAV University in Venice (Italy), and a PhD in Architecture from Griffith University in Brisbane (Australia). He has 20 years professional experience as architect, 6 years of which were in Italy, 10 years in Australia, and 4 years in Middle East. He has 16 years teaching experience at university - 6 years in Italy, 6 years in Australia and 6 in Middle East.

Sara Zaina graduated from The University of Sydney [B. Arch-University of Sydney (Australia)] and from Qatar University [Master in Urban Planning and Design]. She has honourably received many prestigious Architectural Awards in Australia; many of her projects have been selected to be showcased in exhibitions. She has acquired over 3 years of working experience as an Architect.

Shikha Patel holds a Bachelor's Degree in Architecture from Gujarat University, India and a Master's Degree in Urban Design from VTU, Bangalore, India. She has two years of work experience as a junior architect in private practice along with 4 years of experience as an Assistant Professor. Currently, she is employed as a research assistant at Qatar University under the Collaborative Grant research scheme [QUCGCENG-19_20-4] titled "The Action Plan for the Implementation of Qatar National Masterplan based on Integration of Land Use and Public Transport Systems", led by Dr. Raffaello Furlan 